\title{
Author Correction: Human fingerprint in global weather
}

\author{
Seung-Ki Min (D) \\ Published online: 9 January 2020 \\ https://doi.org/10.1038/s41558-020-0689-0 \\ ๑ Springer Nature Limited 2020
}

Correction to: Nature Climate Change https://doi.org/10.1038/s41558-019-0670-y, published online 2 January 2020.

In the version of this News \& Views originally published, the ref. 5 author surnames Meihnausen, Fisher and Szekely were spelled incorrectly; they should have been spelled Meinshausen, Fischer and Székely, respectively. This has now been corrected.

\section{Addendum: Substantial twentieth-century Arctic warming caused by ozone-depleting substances}

\author{
L. M. Polvani (D), M. Previdi (D), M. R. England (D), G. Chiodo (D) and K. L. Smith \\ Addendum to: Nature Climate Change https://doi.org/10.1038/s41558-019-0677-4, published online 20 January 2020.
}

At the request of the authors the below listed changes have been made to the text of this Letter for clarity; the results of the research are not affected by these changes.

The sentence 'ODS, therefore, are responsible for one-third of the global warming over that period, which is in line with their RF' has been changed to 'In the absence of increasing ODS, therefore, global warming would have been one third smaller over that period'.

The sentence 'In CAM5LE, therefore, ODS contributed one-half of forced Arctic surface warming in the latter half of the twentieth century' has been changed to 'In CAM5LE, therefore, ODS contributed almost $0.8^{\circ} \mathrm{C}$ to forced Arctic surface warming in the latter half of the twentieth century.

The sentence 'In CAM5LE, therefore, ODS contributed one-half of the forced Arctic sea-ice loss in the latter half of the twentieth century' has been changed to 'In CAM5LE, therefore, ODS contributed nearly $0.7 \times 10^{6} \mathrm{~km}^{2}$ to the forced Arctic sea-ice loss in the latter half of the twentieth century'.

The sentence 'This is perhaps not surprising, given that ODS contribute one-half of the change in Arctic $T_{s}$ and September SIE for the period 1955-2005' has been changed to 'This is perhaps not surprising, given that ODS contribute a substantial fraction of the change in Arctic $T_{\mathrm{s}}$ and September SIE for the period 1955-2005.

The sentence 'How can ODS, which contribute only 20\% of the GHG RF over the Arctic over that period (see Methods), cause one-half of the forced surface warming and sea-ice loss?' has been changed to 'How can ODS, which contribute only 20\% of the GHG RF over the Arctic over that period (see Methods), cause such a large forced surface warming and sea-ice loss?'

The following paragraph has been inserted before the last paragraph of the main text: 'Beyond the specific physical mechanisms responsible for the high efficacy of ODS on the Arctic climate system, it is important to place ODS in the context of the other anthropogenic forcings. As seen in Fig. 1, the largest RF is associated with $\mathrm{CO}_{2}$, and it is three times larger than the RF from ODS, over the 1955-2005 period. At the same time, anthropogenic aerosols are believed to have produced a considerable, yet highly uncertain, negative ${ }^{7} \mathrm{RF}_{\text {. }}$ Without the large cancellation from aerosols the relative contribution of ODS to the total forced Arctic climate change would be smaller. However, irrespective of aerosols, the absolute contribution of ODS—nearly $0.8^{\circ} \mathrm{C}$ of warming and $0.7 \times 10^{6} \mathrm{~km}^{2}$ of September sea ice loss over only 50 years-is remarkably large.'

The sentence 'Our model integrations show that, in addition to being the key drivers of stratospheric ozone depletion (notably over the South Pole), ODS have been important players in the global climate system, producing about one-third of global warming and one-half of Arctic climate change over the second half of the twentieth century' has been changed to 'Our model integrations show that, in addition to being the key drivers of stratospheric ozone depletion (notably over the South Pole), ODS have been important players in the global climate system, notably in the Arctic, over the second half of the twentieth century'.

The following sentence has been added to the end of the Acknowledgements: 'The authors are indebted to P. Forster and J. Fyfe for suggesting an important clarification'.

Published online: 28 January 2020

https://doi.org/10.1038/s41558-020-0711-6

(C) The Author(s), under exclusive licence to Springer Nature Limited 2020 